\title{
EXPERIENCIANDO VIVÊNCIAS DA FORMAÇÃO MULTIPROFISSIONAL EM EDUCAÇÃO PERMANENTE EM SAÚDE
}

\section{EXPERIENCING EXPERIENCES OF MULTIPROFISSIONAL TRAINING PERMANENT HEALTH EDUCATION}

\author{
Eduarda Signor, ${ }^{1}$ Fernanda Hampe Picon, ${ }^{2}$ Luiz Anildo Anacleto da Silva, ${ }^{3}$ Teresinha Heck Weiller ${ }^{1}$ \\ ${ }^{1}$ Universidade Federal de Santa Maria/Santa Maria/Brasil. ${ }^{2}$ Universidade Federal do Rio Grande do Sul/Porto Alegre/Brasil. ${ }^{3}$ \\ Universidade Federal de Santa Maria/Palmeira das Missões/Brasil.
}

Autor correspondente: Eduarda Signor e-mail: eduardasignor@hotmail.com

\section{EDITORES}

Thiago Gomes Heck

(Unijuí-Brasil)

Adriane Cristina Bernat Kolankiewicz (Unijuí-Brasil)

\section{EDITORES DE ÁREA}

Educação \& Saúde

Eva Teresinha de Oliveira Boff

(Unijuí-Brasil)

Fisioterapia \& Saúde

Eliane Roseli Winkelmann

(Unijuí-Brasil)

Ciências Farmacêuticas \& Saúde

Marilei Uecker Pletsch

(Unijuí-Brasil)

Nutrição \& Saúde

Lígia Beatriz Bento Franz

(Unijuí-Brasil)

Nadia Oliveira

(Unipampa-Brasil)

Ingrid Perry

(UNESC-Brasil)

Enfermagem e suas contribuições para a prática

Adriane Cristina Kolankiewicz

(Unijuí-Brasil)

Crhis de Brum

(UFFS-Brasil)

Neila de Souza

(UFSM-Brasil)

Exercício Físico \& Saúde

Thiago Gomes Heck

(Unijuí-Brasil)

Anderson Zampier Ulbrich

(UFPR)

Editora Unijuí

Universidade Regional do Noroeste do

Estado do Rio Grande do Sul (Unijuí

\section{RESUMO}

Este estudo tem como objetivo relatar a experiência sob a perspectiva discente realizada durante o curso de especialização em Formação Multiprofissional em Educação Permanente em Saúde, disponibilizada pelo Ministério da Saúde, em parceria com a Universidade Federal do Rio Grande do Sul. O curso ocorreu com momentos de Educação a Distância, com participação na Plataforma de Aprendizagem do Observatório de Tecnologias de Informação e Comunicação em Sistemas e Serviços de Saúde. Para comunicação entre os participantes foram disponibilizadas ferramentas de fóruns, diário cartográfico e caixa de afecções. Foram realizados cinco encontros presenciais elencados conforme necessidade dos discentes. $\mathrm{O}$ grupo era composto por sete alunos do curso de Especialização e um do curso de Aperfeiçoamento, além de uma tutora. A partir das experiências vivenciadas no decorrer do processo de aprendizagem do curso, são relatados os conhecimentos adquiridos e experiências vivenciadas e apresentadas pela turma, agregando conhecimentos mais amplos acerca do processo de trabalho específico de cada profissional.

Palavras-chave: Educação permanente. Educação a distância. Especialização. Enfermagem.

Submetido em: 18/6/2016

Aceito em: 19/10/2016 


\section{Revista}

\section{Contexto}

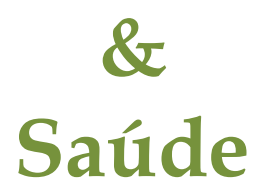

Volume 16

Número 31

2016

ISSN 2176-7114

\begin{abstract}
This study aim store port the experience in the student perspective held during the course of specialization in Multidisciplinary Training in Continuing Health Education provided by the Ministry of Health in partnership with the Federal University of Rio Grande do Sul. The course took place with moments of Distance Education, with participation in Centre Information and Communication Technologies in Health Systems and Services, Learning Platform. For communication between the participants, it was available forums tools, daily chart and conditions box. Listed face meetings as required of students were carried out. The group consisted fever students of specialization and a course of training in ad dithionate a guardian. From the experiences lived during the course of the learning process, it is reported the acquired knowledge and life experience sand presented the classadding broader knowledge about the specific of each professional work process.
\end{abstract}

Keywords: Education Continuing. Education Distance. Specialization. Nursing.
A Revista Contexto \& Saúde é um periódico do Departamento de Ciências da Vida da Universidade Regional do Noroeste do Estado do Rio Grande do Sul (Unijuí). É um periódico semestral que tem por objetivo a divulgação da produção técnico-científica de temas relacionados à área de Ciências da Saúde.

O escopo da revista abrange a divulgação de resultados de pesquisa que contemplem avanços no processo saúde-doençacuidado e no conhecimento e aplicabilidade de novos processos químicos e biológicos em saúde.

Neste periódico, entende-se que a publicação de estudos com os aspectos epidemiológicos, assistenciais e educacionais em saúde, experimentais e aplicados é uma forma a subsidiar e qualificar a atenção à saúde de modo interdisciplinar. 


\section{INTRODUÇÃO}

Anteriormente a formação profissional em saúde pautava-se na utilização de métodos conservadores/tradicionais, influenciados pelas teorias cartesiano-newtonianas, fragmentadas e reducionistas (CAPRA, 2006). Nesta concepção educativa, há uma dicotomia que separa o corpo da mente, a razão do sentimento, ciência da ética, secionando o saber altamente especializado, buscando eficiência técnica (CAPRA, 2006; BEHRENS, 2005). Essa desintegração do conhecimento foi apresentada pela subdivisão da universidade em centros e departamentos e dos cursos em disciplinas, conteúdos e semestres. Nesta continuidade, o processo ensino/aprendizagem tem-se limitado à reprodução do conhecimento, em que os docentes assumem funções de transmissores de conhecimentos, e por outro lado, cabem aos discentes a memorização e a replicação dos conteúdos a eles destinados, tornando-os meros espectadores sem opinião crítica e/ou reflexiva (BEHRENS, 2005).

O ensino superior em saúde, no entanto, vem passando por mudanças na forma de conduzir a formação profissional e docente. Por isso, o ensino tradicional vem sendo substituído gradualmente por novas metodologias pedagógicas, que visam à formação de um profissional crítico e reflexivo, que esteja apto para transformar a realidade social e seu processo de trabalho, minimizando as diferenças e assim melhorando a qualidade de saúde da população, seguindo os princípios do Sistema Único de Saúde (SUS) (RODRIGUES; ZAGONEL; MANTOVANI, 2007).

Assim, são realizadas discussões acerca do estabelecimento de ações de educação em saúde no Ensino Superior, juntamente com a necessidade de qualificar profissionais que trabalham em consonância com os princípios do SUS e que estão presentes nas instituições de ensino e na esfera governamental da saúde. Por isso, o Ministério da Saúde tem procurado integrar as políticas públicas aos serviços de saúde, buscando correlacionar a assistência prestada aos usuários com a prática na Graduação. Ademais, os profissionais que atuam na saúde pública devem envolver o conhecimento com o domínio técnico-científico, por meio da área da saúde, integrado a outros serviços governamentais (XAVIER; LILIAN, 2011; CECCIM; FEUERWERKER, 2004).

O processo de ensino/aprendizado torna-se um somatório de atividades articuladas, com diversos protagonistas assumindo responsabilidades e compromissos. Nesse sentido, é fundamental que a concepção de "depósito de conteúdos", que visa à memorização sem limites seja superado, substituído pela educação liberadora, uma prática política que exige reflexão e que é capaz de produzir novos pensamentos e entendimentos do mundo, tornando-se um indivíduo que seja crítico, criativo, comprometido e responsável (FREIRE, 1987, 1994).

Faz-se necessário aprofundar e ampliar as definições criadas a partir da participação dos discentes, cabendo aos docentes o exercício da reflexão, acompanhamento da pesquisa e cuidado, prognosticando emergências às situações repentinas e inexploradas (MITRE, 2006).

Na concepção de Berbel (2011), os docentes procuram conduzir os futuros profissionais pela utilização de metodologias ativas, buscando despertar a motivação e autonomia, fortalecendo a percepção dos discentes para serem origem de sua própria ação, ao ser exibidas oportunidades de problematização a partir das situações estabelecidas pelos docentes, que oportunizam caminhos possíveis ou soluções criativas para os problemas apresentados. As metodologias ativas conseguem despertar a curiosidade nos alunos, na medida em que estes trazem elementos novos, ainda não apresentados em aula. Nessa perspectiva, analisadas e consideradas as contribuições vindas dos alunos, estes sentem-se valorizados e os sentimentos de comprometimento, competência e pertencimento são estimulados. 
Para a mesma autora, as metodologias ativas são baseadas na forma como é desenvolvido o processo de aprendizado, na utilização de experiências reais ou não, favorecendo condições para solucionar os desafios vindos das atividades realizadas na prática, em seus diversos contextos (BERBEL, 2011).

Nesse sentido, o curso de especialização em Formação Integrada Multiprofissional em Educação Permanente em Saúde objetiva realizar conexões de experiências de trabalhadores e gestores do SUS na perspectiva da Educação Permanente em Saúde (EPS). Além do mais, realizar invenções de práticas de aprender, cuidar e fazer/viver a EPS, potencializando o processo de "trabalho vivo em ato". Assim, autores descrevem o trabalho vivo em ato em duas dimensões: a atividade como construtora e realizada por meio de produtos, que estão ligados à realização de finalidade para o produto; e a outra está vinculada ao produtor do ato, ou melhor, o trabalhador e suas relações com o ato produtivo que está sendo realizado, bem como a relação com os demais trabalhadores e usuários do seu produto (MERHY; FRANCO, 2006).

Diante disso, o objetivo deste artigo é relatar a experiência acadêmica na Formação Integrada Multiprofissional em Educação Permanente em Saúde e discutir suas contribuições como estratégia de ensino-aprendizagem em espaços formativos na área da saúde.

\section{MÉTODO}

Trata-se de um relato de experiência desenvolvido por uma discente do curso de Educação a Distância (EaD) de Especialização em Formação Integrada Multiprofissional em Educação Permanente em Saúde promovida pelo Ministério da Saúde em parceria com a Universidade Federal do Rio Grande do Sul, para a obtenção do título de especialista. O objetivo do curso foi ativar os processos de EPS nos territórios, assim reconhecendo as práticas e os saberes que existem no cotidiano dos trabalhadores do SUS, produzindo novos sentidos no fazer saúde.

A especialização é direcionada à profissionais atuantes ou vinculadas ao SUS. O curso teve carga horária de 390 horas, distribuídas em 3 semestres letivos. A turma é integrada por 7 alunos do curso de Especialização e 1 do curso de Aperfeiçoamento, com carga horária diferenciada. Entre eles são: 3 enfermeiros, 2 psicólogos, 1 terapeuta ocupacional, 1 contador e 1 psicólogo (curso de Aperfeiçoamento).

Para comunicação entre os discentes foi disponibilizado um portal on-line do Observatório de Tecnologias de Informação e Comunicação em Sistemas e Serviços de Saúde (Otics) com opções de diário cartográfico, caixa de afecções, entradas de textos e fórum. Este portal serve como espaço de interação direta entre os participantes, as tutoras e a equipe de apoio pedagógico. Foi acordado na turma uma rotina quinzenal de escrita e interação com os demais membros do grupo.

O curso teve início em agosto de 2014. Os encontros foram mediados pela tutora, inicialmente semestralmente, e após consentimento dos integrantes do curso, foi decidido pela realização de encontros mais frequentes, ocorrendo a cada dois meses. No total foram realizados cinco encontros presenciais.

\section{RESULTADOS E DISCUSSÕES}

No século 20, Flexner produziu estudos que se tornaram base para a estruturação do ensino e para a elaboração dos currículos das faculdades de Medicina americanas e, mais tarde, para o mundo todo. Proporcionou também o desenvolvimento do ensino tradicional com foco no docente (FLEXNER, 1910). 
O ensino tradicional foi organizado em disciplinas, e posteriormente, constituído em departamentos, com estrutura autônoma (CHAUÍ, 1980). Nesse modelo de ensino as aulas são ministradas para turmas fechadas, em formato de palestras ou conferências, quando a transmissão dos conteúdos é muito valorizada. Os alunos recebem estas informações de forma passiva, sem ter participação ativa no seu próprio aprendizado, e diversas vezes falta tempo para a realização de outras atividades que não seja estudar para as provas, que por sua vez avaliam a quantidade e profundidade das informações adquiridas (FLEXNER, 1910).

A educação superior, portanto, tem passado por profundas mudanças visando acompanhar as concepções que apontam para a formação profissional e docente. Assim, o modelo tradicional vem sendo substituído gradualmente por novas tendências pedagógicas, que dão enfoque à formação de discentes críticos e reflexivos, capazes de transformar a realidade do cotidiano, minimizando injustiças e desigualdades, e uma educação comprometida com a qualidade de saúde oferecida à população, atendendo os princípios do SUS (RODRIGUES; ZAGONEL; MANTOVANI, 2007).

Cada vez mais a EaD vem sendo compreendida como uma importante estratégia de qualificação profissional. Assim, faz-se necessário a transformação e capacitação dos profissionais que atuam na saúde. Deste modo, a EaD coloca-se como uma estratégia diante dos desafios de integração dos novos métodos pedagógicos transformadores da realidade (PAIM; GUIMARÃES, 2009).

As metodologias ativas são estratégias que colocam os alunos como protagonistas e responsáveis pela própria trajetória educacional. Já os docentes entram em plano secundário, atuando como facilitadores de experiências do processo de aprendizagem (REIBNITZ; PRADO, 2006). A utilização de metodologias ativas, porém, ainda é um grande desafio para os docentes, pois para a sua utilização, é necessário conhecer os diversos modelos operacionais e os princípios pedagógicos críticos (PRADO et al., 2012).

\section{Relatando a vivência da formação da práxis em educação permanente em saúde}

Ao ingressar no curso de Especialização, em agosto de 2014, foi optado pela realização do curso no município de Porto Alegre, no Estado do Rio Grande do Sul, o qual tinha por objetivo experimentar diferentes vivências em relação às situações já reconhecidas no município de residência, Santa Maria, também polo da especialização. Assim, iniciou-se o curso, em outra cidade, com outros colegas, com outras tutoras. Enfim, tudo novo.

No ensino tradicional existe cronograma com datas e horários preestabelecidos a serem seguidos, ao contrário dos objetivos propostos pelas metodologias ativas, em que o aluno se dedicava ao curso e acessava a plataforma nos horários que lhes fossem mais convenientes e propícios. No início houve estranhamento pela maioria dos discentes, que relatavam não estarem acostumados com este novo modelo de ensino. Os alunos relatavam que sentiam falta de ter horários estabelecidos para a entrega de trabalhos.

São destacados alguns trechos do diário, no qual foram descritas vivências no decorrer do curso. Em julho de 2015 foi relatado quanto ao método de ensino tradicional. Como segue: 


\section{Reflexão}

Esta semana parei para refletir acerca do processo avaliativo que as Universidades utilizam. Frequento o curso de especialização em Gestão Pública em Saúde EaD na qual temos portal para acessarmos as disciplinas, notas, tarefas, fóruns, chat (...). Cada disciplina tem uma apostila de aproximadamente 200 páginas de texto corrido (sem imagens, figuras...). Também temos 2 trabalhos para entregar com data pré estabelecida, 2 fóruns para realizar comentários e mais 2 provas teóricas presenciais, bem como o exame. Há docentes e tutores disponiveis para sanar dúvidas e realizar demais comunicações no decorrer do curso.

Quando estou sendo avaliada através de trabalhos, "provas" e chat (onde todo mundo copia algo e posta, até sem ler...) sintome tão impotente, pois até a palavra 'prova' é algo forte. Quem nunca ficou angustiado na véspera? Por que sentir isso? É o sentimento mais desnecessário que alguém em formação poderia sentir.

Ano passado cursei uma disciplina de Metodologias Ativas. Foi a melhor que já fiz. Deu muito trabalho, mas valeu a pena cada minuto. Tínhamos que construir com portfólio (como se fosse o diário cartográfico), tudo era livre, sentimentos, emoções, desenhos, fotos. Ainda, começamos elegendo assuntos e questões para serem discutidos nas aulas, conforme a necessidade dos alunos enquanto futuros docentes. Criávamos uma questão para ser respondida, porém ela não tinha uma única resposta pronta, tínhamos que construir a resposta para discutir em aula. Pesquisávamos por textos, que talvez fossem relacionados com a questão, após realizar a leitura de muitos e muitos textos, conseguíamos fazer uma síntese. Com o decorrer, passamos a ler os textos e não mais fazer resumo e sim fluxogramas, gráficos, desenhos...

O exercício foi fantástico, pois fazer um síntese de uma questão que não tem resposta pronta não é fácil...

Também, a avaliação da disciplina e das aulas eram chamadas de "encontro a dois" onde aluno e o professor, conversavam sobre as potencialidades e fragilidades do todo. Ainda, realizávamos auto-avaliação elencando pontos principais. Pois o professor não é o detentor do saber, e os alunos devem mostrar o que eles sabem e o que eles acham que podem melhorar.

O primeiro encontro foi totalmente diferente do que somos ou fomos acostumados a presenciar, sem aulas expositivas ou apresentação de slides, sem processos avaliativos, sem datas ou cobranças. Diferente também pelo fato de ser o primeiro contato com a "nova" turma, de outro município, outra realidade. Assim, discentes de diversas áreas do SUS foram interagindo acerca de suas experiências e transformações no cotidiano de trabalho. Foi sugerido sentar em roda, para proporcionar a todos a oportunidade de fala, escuta e participação ativa. Também foram acordadas metas para o decorrer do curso e apresentada a plataforma de comunicação online, em que foram exemplificados alguns itens presentes, que serviriam como forma de avaliação e interação acerca do processo e andamento do curso.

Este primeiro contato com o curso nos desacomodou perante as diferentes atividades propostas. Nos sentimos desorientados em relação a não ter prazos para entrega de trabalhos e por não haver trabalhos a serem entregues rotineiramente, e também no sentido de estarmos cursando Especialização EaD, havendo encontros presenciais, porém estar ali como próprio construtor do conhecimento, todos ensinando e aprendendo em conjunto.

No segundo encontro foi acordado entre todos os discentes e tutoras aumentar o número de encontros presenciais, visando à maior qualificação profissional dos alunos. Assim, cada área da saúde conseguiu se 
conectar com as outras áreas, construindo assim uma rede dentro do curso. Corroborando com isso, Ceccim traz que essas ligações devem ser capazes de organizar as práticas a partir de redes de apoio, ofertando a pedagogia da EPS para que ela faça sentido e opere em processos significativos na realidade (CECCIM, 2005).

Também, no segundo encontro, foram acordados alguns itens acerca do trabalho final:

\section{Segundo encontro da Especialização em Educação Permanente em Saúde em Movimento (18/04/2015)}

Desde o primeiro encontro do curso era perceptivel a empolgação de todos. Com o passar das semanas, as demandas diárias tomavam espaço de mais. No entanto, na medida do possível ficava online na plataforma. Ainda com algumas dificuldades de acesso na plataforma, aos poucos estou agilizando o processo. Meu processo de aprendizagem e desenvolvimento durante 0 curso foi satisfatório, sempre utilizando das entradas como aporte teórico. Acompanhei os diários cartográficos dos colegas, no entanto, não cheguei a deixar meu depoimento mas, acompanhava sempre que possivel. Acrescentei algumas entrada que considero 'clássicos' da temática e trabalhos publica dos recentemente. Interagir algumas ocasiões com a tutora, mas nada de excesso.

Na primeira parte da manha, escrevemos a auto-avaliação de forma criativa' porém como ainda era cedo, minha criatividade não passou de palavras escritas.

No segundo momento da manhã, acordamos alguns pontos:

- trabalhar na plataforma de forma cole tiva relatando vivências, sempre tendo em evid ência os preceitos éticos.

- TCC da especialização em formato ABNT em 10 a 30 páginas.

- relatar nosso processo de aprendizagem, relatar mudanças que ocorreram.

- postar idéias, opiniões ou deixar comentário de que passou pelo diário do colega.

Após o intervalo do almoço, retornamos e pactuamos com os grupos pequenos:

- acessada plataforma ao menos uma vez na semana, comentando no diário dos colegas.

- participar do coletivo semanalmente, interagindo no fórum.

- criar legenda ou resumo na postagem na caixa de afecções, para que os demais compreendam .

Porque eu gostaria de publicar?

Até onde a gente vai com a liberdade que a gente tem? E onde a gente vai com a liberdade que a gente tem?

Pra quem eu escrevo?

No segundo momento da tarde, as tuto ras leram uma mensagem. A primeira sobre Jonas na baleia e a segunda de Eduardo Galeano.

Segundo encontro muito especial, marcado de muitas falas especiais.

19 de abril de 2015 .

Eduarda Signor

No terceiro encontro, todos já ambientados com a plataforma e com a metodologia do curso, ocorreram diversas discussões sobre as experiências vivenciadas pelos profissionais ali presentes, que abordavam o cotidiano de trabalho sempre levando em consideração a postura ética, preservando a identidade do local de trabalho pelo fato de a maioria dos cursistas residir na cidade, a fim de não expor diretamente as instituições. 
A partir do terceiro encontro, além de experienciar as vivências do cotidiano, também deu-se início aos primeiros passos do TCC. Foram realizadas conversas acerca das temáticas que os trabalhos seguiriam. Sempre sentávamos em roda, o que foi produtivo, pois as conversas fluíam naturalmente e todos conseguiam participar de forma espontânea. A autonomia dos discentes perante as discussões causou estranhamento em um primeiro momento, no entanto sempre buscou-se possibilitar discussões acerca das situações vivenciadas pelos gestores e equipes, por meio das ações que ocorriam no cotidiano de trabalho individual ou coletivo.

É trazido então, um trecho do diário cartográfico, de maio de 2015, em que foi relatada a dificuldade inicial em escrever acerca dos sentimentos e pensamentos no diário. Em alguns momentos, paramos para refletir acerca das dificuldades em escrever sobre os sentimentos, e essa dificuldade ocorre por não sermos incentivados a escrever o que sentimos e o que pensamos. Somos ensinados a decorar conteúdos e reproduzir em provas sobre o que foi aprendido ou decorado. Já a proposta do curso foi totalmente outra; desacomodar e fazer pensar a respeito das vivências e da realidade. Acreditamos que a dificuldade em escrever a respeito dos momentos se dá por este motivo. Segue um trecho do diário:

27 de maio de 2015. Eduarda Signor

Fazem dias que apenas entro na página, porque não consigo me colocar aqui.

Esta dificuldade, no entanto, foi relatada pela grande maioria dos integrantes do curso. Ao ler os diários cartográficos dos demais colegas foi identificada também a mesma carência na escrita. No decorrer do curso fomos compreendendo as raízes do diário cartográfico, e a partir de conversas durante os encontros, conseguimos expressar a escrita. Assim, o crescimento foi individual e coletivo, pois um dos objetivos também era acompanhar a escrita dos colegas, assim foi possível perceber que todos cresceram de forma a contemplar as prioridades do curso.

A partir das transformações que ocorreram ao longo da caminhada do presente curso, foi observado crescimento como profissionais em relação a algumas práticas docentes realizadas. Neste sentido, foram aplicados em aula problemáticas (casos clínicos) e conteúdos ministrados a partir de metodologias ativas, plano de melhoria aos alunos (que apontavam suas próprias potencialidade e fragilidades) e ao final das aulas, uma sucinta autoavaliação e avaliação da aula.

O que motivou para a realização destas ações em aula foi por ter cursado uma disciplina de metodologias ativas, como aluno especial do curso de Doutorado em Enfermagem. A experiência de poder falar e expressar o que queríamos aprender motivou para a realização de atividades com os futuros alunos. Também, após concluir a disciplina e ingressar no presente curso de especialização, houve motivação para a realização desta experiência com os alunos, na docência orientada do curso de Mestrado em Enfermagem. Foi uma tarefa difícil fazer com que alunos de Graduação, cansados dos estágios, participassem de forma ativa do processo, e mesmo propondo atividades diferenciadas foi difícil atrair a atenção de todos. 


\section{Diário Cartográfico}

No portal Otics haviam ferramentas disponíveis, como o Diário Cartográfico, que possibilitou a produção de visibilidades e dizibilidades aos fatos e afecções que instituem na produção da vida, afetos e práticas (DELEUZE; GUATTARI, 1995). Assim, para concretizar a produção, faz-se necessário estar aberto para os encontros e as afeções ali produzidas. Para produzir não é necessário seguir regras ou métodos, mas dar espaço para a inventividade e criação, podendo utilizar diversos recursos para dar forma às afecções (EPS EM MOVIMENTO, 2014a).

Rolnik (2014) afirma que esta proposta não se efetiva no plano teórico, mas sim no que se refere às vivências e experiências que nos cercam. Nada de convencional, falamos de um desenho que dialogue com os acontecimentos e afetações do cotidiano pessoal e profissional.

Como primeira impressão do diário cartográfico, foi questionado: Como expressar as vivências e experiências do cotidiano de trabalho? Por isso, a proposta da Especialização era desacomodar, investir na realização de movimentos a partir das afetações que acorriam no dia a dia. Assim, foi dado o pontapé inicial para a construção do conhecimento a partir do diário cartográfico, e a partir da leitura e acompanhamento dos demais diários, aos quais todos tinham acesso. No diário, foi optado por inserir a data da postagem, para que se pudesse acompanhar o processo de aprendizado, a escrita e evolução no decorrer do curso.

Todos os demais colegas do curso também relatavam suas experiências, vivências e transformações no processo de trabalho. Nisto, a partir da leitura e reflexão da escrita dos colegas, foram associadas algumas fragilidades encontradas no decorrer do processo de aprendizado, visto ter atuado apenas na área acadêmica. Os relatos dos colegas ajudaram a compreender sobre algumas situações cotidianas que ocorrem no trabalho em saúde, que a visão acadêmica não poderia proporcionar.

Em um momento no decorrer do curso, tivemos a oportunidade de realizar uma autoavaliação, a qual foi entregue durante a aula, e inserida no diário cartográfico, pois também fez parte do processo:

\section{Autoavaliação Especialização e Educação Permanente em Saúde em Movimento 17/04/2015}

Copiei minha autoavaliação submetida ao fórum.

"O primeiro encontro em Porto Alegre com a sala de aula praticamente lotada, a motivação com o início de curso era perceptivel. Ao dar inicio ao diário cartográfico, me deparei com o mesmo sentimento de quando fiz um portfolio para uma disciplina de metodologia ativas do mestrado. Eu não conseguia estar ali, eu não conseguia me colocar ali.Meu percurso durante o processo de aprendizagem na especialização acredito que tenha subido alguns degraus, com a colaboração dos diários cartográficos dos colegas e textos das entradas. Minha caixa de afecçôes não está atualizada, porém, muitos textos que estão ali tem algum sentido em minha vida. Não tenho me comunicado muito com os colegas, mesmo tentando estar online semanalmente na plataforma, acompanhando as novidades. Tenho dificuldade ainda em alguns pontos da plataforma, mas aos poucos vou melhorando minha agilidade. Acompanho as publicações dos colegas na medida do possível, porém nunca dissertei na página. Obtive diversas orientações produtivas com a tutora, também não com muita frequência. Contribui com o coletivo na medida em que textos recentes ou 'clássicos' surgiam no meu cotidiano. Apesar das fragilidades de acesso à plataforma, as potencialidades são maiores."

19 de abril de 2015.

Eduarda Signor

Além deste processo, consta no diário alguns assuntos que são pertinentes enquanto profissionais de saúde e educação, tais como: Educação a Distância e a EPS e como ocorre a gestão dos recursos financeiros da EPS. 
EXPERIENCIANDO VIVÊNCIAS DA FORMAÇÃO MULTIPROFISSIONAL EM EDUCAÇÃO PERMANENTE EM SAÚDE

Temas que foram elencados como parte do processo formativo e que até então necessitava de mais leituras da temática. Assim, o diário cartográfico proporcionou levantar questionamentos e inquietações, levando a realizar leituras mais profundas acerca de assuntos que não foram abordados, porém eram imprescindíveis para o crescimento profissional.

Quanto aos diários dos colegas, foi observado o crescimento no decorrer do curso. Não foi citado, porém a partir da leitura dos diários pôde-se experienciar as vivências que os colegas presenciavam no dia a dia de trabalho. Foi percebido, a partir da leitura dos diários, a mudança e impacto que a EPS causa no cotidiano de trabalho dos colegas.

\section{Caixa de Afecções}

Dentre os recursos da plataforma, também se encontrava a caixa de afecções. Nela estavam disponíveis materiais e havia a possibilidade de anexar arquivos que eram importantes para a construção dessa caminhada. Também todos tinham acesso aos conteúdos que eram anexados pelos colegas, podendo ser realizadas discussões coletivas acerca dos textos postados.

$\mathrm{Na}$ caixa de afecções foi criado um espaço de arquivos relacionados aos objetivos traçados pelo curso e principalmente para registrar as experiências como educador no mundo da vida e do trabalho. Poderíamos inserir na caixa de afecções ideias, sensações, coisas, palavras, arquivos, fotos, vídeos ou qualquer material que fosse significativo estar ali, com o intuito de recordar as vivências e práticas (EPS EM MOVIMENTO, 2014b).

O objetivo da caixa era interrogar as experiências, que desafiam o pensamento abrindo conexões para o vivido, favorecendo a produção e dando passagem aos afetos do dia a dia. Também "transver" o vivido da experiência, colocando ideias, pensamentos e convocar a recriação coletiva dos saberes das experiências de todos (EPS EM MOVIMENTO, 2014b).

A caixa de afecções permitiu a transferência de arquivos que fossem considerados relevantes para o processo de aprendizado. Nela foram compartilhados diversos textos, vídeos, imagens e demais arquivos pelos integrantes do grupo. Assim todos tinham acesso às afecções ali disponibilizadas. Ademais, a caixa de afecções foi uma ferramenta que facilitou o processo de aprendizado durante o curso, pois o que cada aluno considerava relevante para o momento era ali disponibilizado para os demais, podendo aproveitar os textos oportunos para a própria construção do conhecimento e processo de aprendizado.

Assim, a caixa de afecções funcionava como um acervo, e proporcionou realizar leituras que os colegas consideravam imprescindíveis para a formação e crescimento, que acabaram agregando ao processo de aprendizado, inclusive facilitando o desenvolvimento na área da docência por serem assuntos que se relacionavam com a prática na saúde e não somente na temática da Enfermagem, mas também na visão de cada profissional das diferentes áreas de atuação no SUS.

Diversos foram os textos em que pudemos refletir acerca do que foi lido. É destacado um dos textos anexados na plataforma: Educação Permanente em Saúde: desafio ambicioso e necessário, de Ceccim. Este nos fez "rere-repensar" todo o processo de ensino na docência orientada, no curso de Mestrado em Enfermagem. Este texto motivou a realizar diversas indagações a respeito do processo de ensino-aprendizagem.

Um vídeo postado por um colega, “O papel do professor”, marcou profundamente. Nele Rubem Alves, traz a importância do novo tipo de professor, criando futuros adultos que saibam pensar. Condena o processo avaliativo das escolas, os processos seletivos de vestibulares e o modelo tradicional de ensino. Este vídeo causou calafrios e revolta, pelo fato do nosso sistema de ensino ainda ser tão antiquado, pois todos nós 
acabamos sofrendo e deixando de aprender coisas que realmente farão a diferença em nossa vida. Também, para disseminar o conteúdo do vídeo, que afetou profundamente, foi compartilhado em redes sociais visando que pessoas com os mesmos interesses pudessem visualizar a mensagem que Rubem Alves quis nos transmitir.

Foi anexado na caixa dois artigos sobre EPS que foram publicados em revistas, pertinentes à caminhada de construção do conhecimento do curso. Também foi inserida a Política de EPS, e situações problemas relacionadas à temática. Estes pequenos arquivos fazem parte do dia a dia, e foi considerado importante compartilhar com todo o grupo. Assim, esperamos que os conteúdos anexados sirvam de aporte teórico e de reflexão acerca da EPS para os demais colegas do curso, como os materiais que foram anexados por eles nos serviram como construtores, melhor dizendo, potencializadores acerca da EPS.

Todos os conteúdos anexados serviram como subsídio para aprimorar as aulas ministradas no curso de mestrado. Assim, a EPS tornou-se uma ferramenta importante no sentido de acrescer nas práticas docentes, que a partir de estudos realizados acerca da EPS durante a Graduação, a Especialização referida, atrelaram no sentido de aprimorar os conhecimento, as práticas e o modo de pensar a respeito das situações vivenciadas.

\section{CONCLUSÃO}

Na conclusão do curso, há de se destacar que as experiências vivenciadas e apresentadas pelos colegas agregaram conhecimentos amplos acerca de cada processo de trabalho, pois cada aluno tinha uma bagagem que serviu de aprendizado aos demais. Nesse sentido, todos participaram do processo de ensino-aprendizagem.

Buscar métodos que ofertam ações educativas articuladas ao contexto de trabalho é fundamental para a construção do conhecimento, também possibilitando a experimentação de novas possibilidades metodológicas do processo de ensino-aprendizagem, facilitando a solução de problemas encontrados e vivenciados no dia a dia de trabalho na saúde.

A partir das experiências vivenciadas no decorrer do processo de aprendizagem, é relatado o crescimento como profissional, em relação a algumas práticas docentes que realizadas. Neste sentido, foi aplicado em aula, problemáticas (casos clínicos) e conteúdos ministrados a partir de metodologias ativas, plano de melhoria aos alunos (que apontavam suas próprias potencialidade e fragilidades) e ao final das aulas, uma breve autoavaliação e avaliação da aula.

Também cabe destacar que a partir das leituras advindas dos diários cartográficos e dos textos disponibilizados pelos colegas, somados à convivência com a temática da EPS, serviram como aporte para trabalhar em aula. Assim, a EPS vem transformando diversos caminhos, também na docência, tentando substituir o método tradicional de ensino por métodos mais dinâmicos, que implicam a participação ativa do aluno, como parte do processo de ensino aprendizagem, não o colocando como mero receptor dos saberes.

\section{REFERÊNCIAS}

BEHRENS, M. A. O paradigma emergente e a prática pedagógica. Petrópolis: Vozes, 2005.

BERBEL, N. A. N. As metodologias ativas e a promoção da autonomia de estudantes. Semina: Ciências Sociais e Humanas, Londrina, v. 32, n. 1, p. 25-40, jan./jun. 2011.

CAPRA, F. O ponto da mutação: a ciência, a sociedade e a cultura emergente. Cultrix: São Paulo, 2006. 
CECCIM, R. B. Educação permanente em saúde: desafio ambicioso e necessário. Comunic, Saúde, Educ., v. 9, n. 16, p. 161-177, set. 2004/fev. 2005.

CECCIM, R. B.; FEUERWERKER, L. C. M. O quadrilátero da formação para a área da saúde: ensino, gestão, atenção e controle social. Physis, v. 14, n. 1, p. 41-65, 2004.

CHAUÍ, M. Ideologia e educação. Educação \& Sociedade, São Paulo; Campinas: Cortez; Autores Associados; Cedes, n. 5. p. 24-40, jan. 1980.

DELEUZE, G.; GUATTARI, F. Mil platôs - capitalismo e esquizofrenia. Tradução Aurélio Guerra Neto e Célia Pinto Costa. 1. ed. Rio de Janeiro: Ed. 34, 1995. p. 94. Vol. 1.

EPS EM MOVIMENTO. O diário cartográfico. 2014a. Disponível em: <http://eps.otics.org/material/entradaapresentacao/apresentacao-diario-cartografico>. Acesso em: 20 dez. 2015.

Caixa de Afecções. 2014b. Disponível em: 〈http://eps.otics.org/material/entrada-experimentacoes/caixa-de-afeccoes〉. Acesso em: 21 ago. 2015.

FLEXNER A. Medical education in the United States and Canada. [s.1.]: Carnigie Foudation for the Advancement of Teaching, 1910.

FREIRE, P. Pedagogia da esperança: um reencontro com a pedagogia do oprimido. Rio de Janeiro: Paz e Terra, 1994.

Pedagogia do oprimido. 17. ed. São Paulo: Paz e Terra, 1987.

GUimarÃES, E. M. P.; MARTiN, S. H.; RABEL, F. C. P. Educação permanente em saúde: reflexões e desafios. Ciencia y enfermería, v. XVI, n. 2, p. 25-33, 2010.

MERHY, E. E.; FRANCO, T. B. Trabalho em saúde. In: ESCOLA POLITÉCNICA DE SAÚDE JOAQUIM VENÂNCIO (Org.). Dicionário da educação profissional em saúde. Rio de Janeiro: Escola Politécnica de Saúde Joaquim Venâncio e Estação de Trabalho Observatório de Técnicos em Saúde, 2006. p. 308.

MITRE, S. M. Ativando processos de mudança em uma aldeia de Belo Horizonte: uma experiência com metodologia ativa de ensinoaprendizagem. 2006. Trabalho (Monografia do curso de Especialização em Ativação de Processos de Mudança na Formação Superior de Profissionais de Saúde) - Fundação Oswaldo Cruz, 2006.

. Metodologias ativas de ensino-aprendizagem na formação profissional em saúde: debates atuais. Ciência \& Saúde Coletiva, v. 13, Sup2, p. 2.133-2.144, 2008.

PAIM, M. C.; GUIMARÃES, J. M. M. Importância da formação de docentes em EAD no processo de educação permanente para trabalhadores do SUS na Bahia. Rev Baiana Saúde Pública, v. 33, n. 1, p. 94-103, 2009.

PRADO, M. T. et al. Arco de Charles Maguerez: Refletindo estratégias de metodologia ativa na formação de profissionais de saúde. Esc Anna Nery, v. 16, n. 1, p. 172-177, jan./mar. 2012.

REIBNITZ, K. S.; PRADO, M. L. Inovação e educação em enfermagem. Florianópolis: Cidade Futura, 2006.

RODRIGUES, J.; ZAGONEL, I. P. S.; MANTOVANI, M. F. Alternativas para a prática docente no ensino superior de enfermagem. Esc Anna Nery, v. 11, n. 2, jun. 2007.

ROLNIK, Suely. Cartografia sentimental: transformações contemporâneas do desejo. 2. ed. Sulina: Porto Alegre, 2014.

XAVIER, A. S.; LILIAN, K. Educação superior no Brasil e a formação dos profissionais de Saúde com ênfase no envelhecimento. Interface Comum Saúde Educ., v. 39, n. 15, p. 973-984, 2011. 